\title{
THE DUBLIN JOURNAL \\ OF
}

\section{MEDICAL SCIENCE.}

\author{
OCTOBER 1, 1900. \\ PART I. \\ ORIGINAL COMMUNICATIONE.
}

ArT. XII.-The Delusive Stage of Grave Abdominal Lesions. By J. S. M'ArdLe, F.R.C.S.I.; Surgeon to St. Vincent's; Hospital.

If there is any subject deserving a separate chapter in the bistory of modern surgery it is the question which I desire to refer to in this paper. In no class of case with which I am acquainted are there so many pitfalls as in those where intestinal lesions play a prominent part. After days of anxious watching, and when already we have given up all hopes of recovery, the patient, to the great delight of friends and attendants, expresses himself as much relieved; bright looks, clean tongue, and a fall of temperature herald what seems the dawn of convalescence. The physician congratulates himself that his patient has weathered the storm, and taking little heed of the rapid pulse and the bright eye that indicates so much when properly understood, he ventures on a favourable prognosis. This apparent quiet does not last long; 24 to 48 hours' rest is succeeded by intermittent attacks of mental aberration. accompanied by an erratic temperature; then distension of the abdomen becomes more marked, delirium more persistent, and the pulse too quick to be counted, and when least expected the patient passes beyond all reach of VOL. CXX.-NO. $34 b^{\circ}$, THIRD SERIES. 
earthly help. This stage, which raises hopes soon to be dashed, has not been dwelt upon sufficiently in the literature of medicine, and I, therefore, bring it under your notice, so that hereafter you may recognise the gravity of the situation, and not be led into expressions of opinion which are registered against you when your professional value is being estimated by the public. I can recall many cases in which my hands have been stayed by the over-anxious attendants, who from want of experience conceived that this betterment which was noticeable to the friends and the relations of the patient was real. My belief is that when this stage arrives it is fatal to delay operation even for a short time. The question is sometimes asked, When should we operate in cases of intestinal obstruction? My answer to this question (after an experience of 20 years of operative work) would be, "At once." My reason for this advice is based upon my observation of the calamitous results of delay, and on the absolute safety of properly conducted abdominal sections. It is my firm conviction that in the absence of some element that would certainly prove fatal without operation there should be no mortality in cases of ordinary laparotomy. In the absence of these conditions I have never seen the operation prove fatal, and I shall bring under your notice cases (of great gravity in which operation has succeeded) that should prove conclusively to you the possibilities there are in the adoption of modern methods of surgical interference. These cases extend over the whole field of abdominal surgery, and include examples of all the phases of intestinal disturbance. Before bringing them under your notice, however, I shall try to set before you the causes of death in such affections, so that you may clearly understand how imperative it is to deal early and vigorously with every case of this class that comes under your care. I am constrained to do this because I feel that it is criminal on the part of any man who undertakes the guidance of patients through serious illnesses of this class not to be aware of the rocks ahead through which we have at times to steer the ship of life. It is only by recognising the dangers that one can surely avoid them; and in reviewing the cases which I shall place 
before you I shall endeavour to state clearly the dangers to be apprehended in each class. In the present paper I shall confine myself to the troubles which arise in the different affections of the appendix, and leave for future consideration the other classes of abdominal lesions.

\section{APPENDICECTONY.}

Before detailing the cases separately, I desire to call attention to the method of operation I invariably carry out, unless prevented from doing so by pathological conditions, which occasionally arise in the course of these cases. I open the abdomen in the right semilunar line, going directly through all the layers of the abdominal wall. My first care on entering the abdomen is to satisfy myself as to the condition and attachments of the great omentum. If it is free it is simply raised upwards out of the way, the patient being in the Trendelenberg position; if it be adherent it is detached or cut across, according as the condition demands, and as will be shown in the details of the cases as we come to study them. Next the cxcum is drawn well into the abdominal wound, and the exact

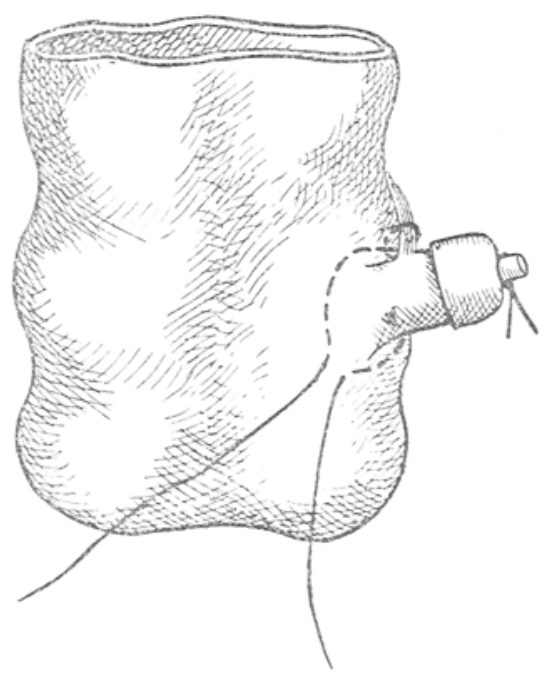

Fig. 1,-Purse-string inverting suture. 
position of the appendix is ascertained; if it be free it is drawn through the wound; if there are adhesions they are broken down; and should its mesentery be so short or so distorted as to prevent its proper exposure, double ligature and section of this fold of peritoneum is carried out. This procedure is especially necessary in cases of corkscrew appendix. Once the intestine is free and the mesentery cut, a purse-string suture is applied round the root of the appendix (Fig. 1). This suture engages the serous and muscular coat of the cæcum, and it should be inserted as shown in Fig. 1-that is, it should commence at a point opposite to the mesentery; when it reaches the latter it should embrace the mesenteric edge in a loop, and then continue on the opposite side of the appendix to its starting point. This suture is left loose until the final step of the operation. I now cut through the sero-muscular wall of the appendix half an inch from its base, and turn downwards like a cuff the tissues set free by this incision, as at Fig. 2.

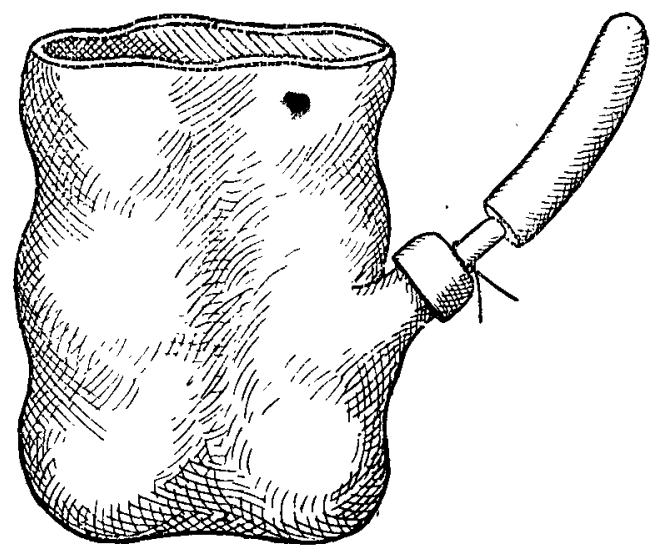

Fig. 2.

A ligature now is placed on the remaining central portion of the appendix, and the parts above it removed. With a small scoop I now curette a brownish centre of the stump above ligature, so as to remove any infective material 
that may be present. This spot is then touched with corrosive sublimate solution, 1 in 500 ; next the cuff above referred to is unfolded; inversion is brought about at its mouth by a single Lembert's suture. The nipple-like projection thus produced is now pushed into the cavity of the cæcum, while the purse-string suture is closed, thus permanently inverting the root of the appendix and thoroughly sealing the opening into the bowel. Where there is glandular enlargement extending along the appendicular mesentery, I make it a rule to separate the layers of

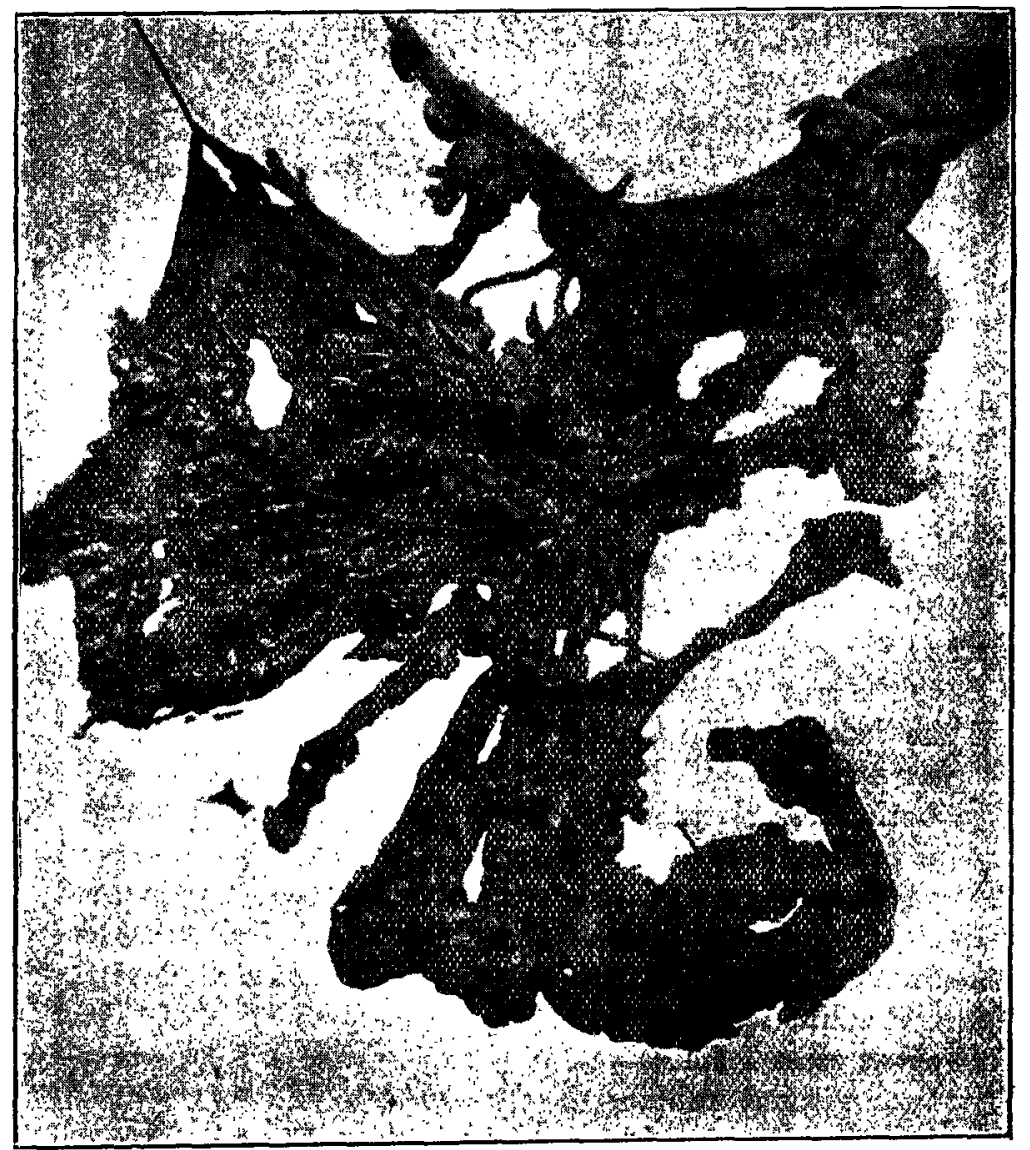

Fig. 3.-Omentum and appendix. 
this membrane and remove the glands, afterwards closing the rent in the peritoneum by fine silk suture. Thus I prevent subsequent inflammatory mischief in the area referred to. When I find the great omentum nodular, adherent, inflamed, or bathed in pus, I make it a point to place a chain suture near its attachment to the colon, and, cutting below the line, I remove the greater part of that membrane, as shown in Fig. 3. This I believe to be specially necessary in cases of perforative appendicitis, and the figure to which I have just alluded represents the parts removed in a case of suppurative peritonitis arising from perforation. In these cases, where the adhesions of the omentum are old and resistent, I prefer to first detach the omentum from the colon and bring it out in the wound, still adhering to the appendix, breaking down in this procedure all secondary adhesions to uterus, bladder, or intestines. By doing this I remove the cause of many untoward troubles which attend less thorough operations. When there has been extensive infection, as in the case just referred to, it becomes necessary to drain, not alone the pelvis, but, as a rule, the right loin. When this is so, I prefer to make, while the first wound is still open, two secondary ones-one midway between the umbilicus and the pubes, through which I place a glass tube in the pouch of Douglas; the second opening is made according to the position of suppuration. If it be primarily extra-peritoneal the incision is made immediately above the crest of the ilium, and passes behind the cacum; if the infection is intra-peritoneal, the incision is made higher up in the loin, and opens into the reno-crcal pouch. In both these situations I use a flanged rubber drain of large calibre, and, as in the case of a glass tube, I insert a long strip of gauze through the tube for capillary drainage. Where suppuration has been extensive I invariably flush the pelvis and loin first with sterilised water, then with normal saline solution, both at a temperature of $104^{\circ}$. In all other cases I am satisfied that mopping up with gauze sponges without rubbing is quite effectual. Before presenting the cases on which I base this communication, I wish to make it quite clear that $I$ am not in accord 
with those who place time limits for the carrying out of appendicectomy. This series will show that at every stage of the disease operation is justifiable and successful.

\section{PERFORATIVE APPENDICITIS.}

Case I.-Miss B., aged thirteen years, came under my care on May 21st, 1898. I saw her late on that evening, and as she was greatly fatigued by the journey I delayed until next morning any surgical interference. Miss $\mathrm{B}$. was sent to me by Dr. M'Caul, of Derry, who had accurately diagnosticated the case.

Now, as the persistent pain, early relapse, and the character of the temperature chart pointed to suppurative trouble, I opened the abdomen by an oblique incision half way between the umbilicus and right anterior superior spine, exposing the ileo-cecal area thoroughly. I found the omentum adherent to the abdominal wall, and through the lower angle of the wound pus welled up. Drawing on the omentum until I reached the edge of the transverse colon, where inflammatory thickening ended, I placed a chain suture all along its root. Clamping the parts below, I cut through the omentum, and turned it with the attached forceps outwards through the wound. The posterior surface thus exposed was fixed by recent adhesions to the aæcum, which came out of the abdomen as a great solid mass. The small intestines were now protected by gauze spongess, the wound being meantime constantly irrigated with boiled water. Breaking down numerous adhesions at the back of the crecum enabled mo to bring the appendix into view. While sweeping my hand round the iliac fossa I came upon a foreign body of very firm consistency, greyish-yellow in colour, and so like a date-stone that for the time there was no doubt but that such a body had found its way to this locality by perforation of the appendix. Fig. 4 represents this body in shape and actual size. Professor McWeeney's report of his examination proved that

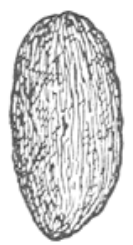

Fig. 4. 
the body was a fæcal concretion. Fig. 5 represents the appendix, which was adherent along the inner and posterior part of the cæcum, and dirped at the point $\mathrm{C}$ into the pelvis. On separating the adhesions I came upon the ragged opening through which the concretion had escaped. I now separated the appendix and its mesentery from the croum and removed them in the ordinary way. As there had been such general peritonitis, and so much pericæcal suppuration, I made an opening close to the anterior superior spine of the ilium and laid in a large drainage tube. The entire abdlominal wound was closed with silkworm-gut sutures.

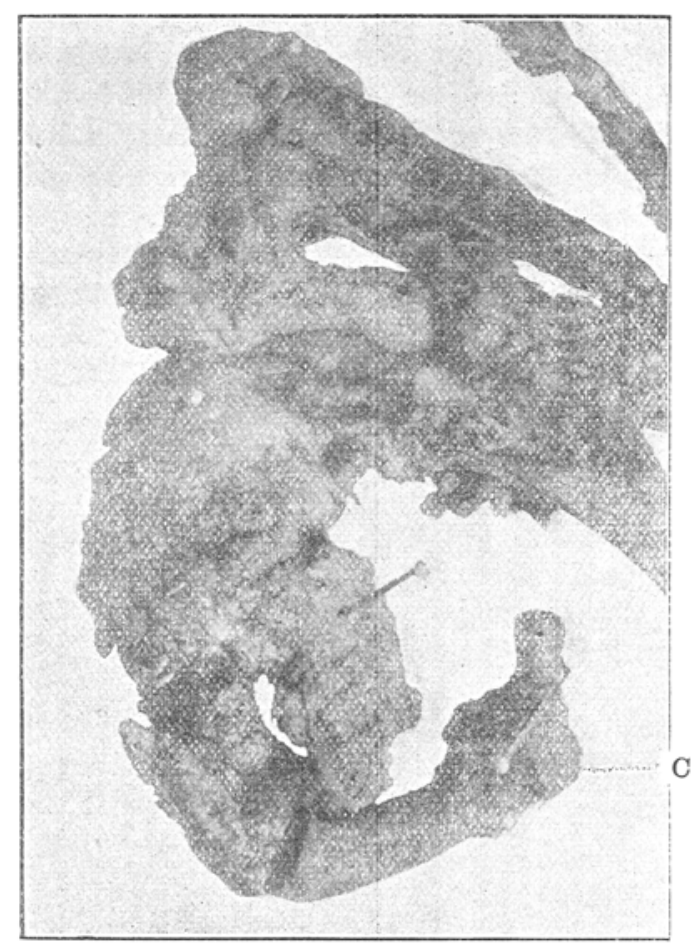

Fig. 5.-Enlargement of appendix.

For a considerable time there was much discharge through the wound at the iliac spine, but by continual douching of the post-cæcal cavity with acetate of aluminin solution, com- 
plete healing occurred, and on the 25 th of November, 1898 , she left hospital looking well and feeling thoroughly restored to health.

\section{CORK-SCREW APPENDIX.}

Case II.-Miss E. J. came under my care, suffering extremely acute abdominal pain, chiefly referred to the right side, coming on suddenly, and attended by vomiting. This pain was very persistent just before and after the early days of menstruation. In none of the attacks was there rise of temperature. Believing that there were adhesions of the appendix in the pelvis, assisted by Dr. Glenn I performed laparotomy, and discovered the appendix as shown in Fig. 6. It was coiled up

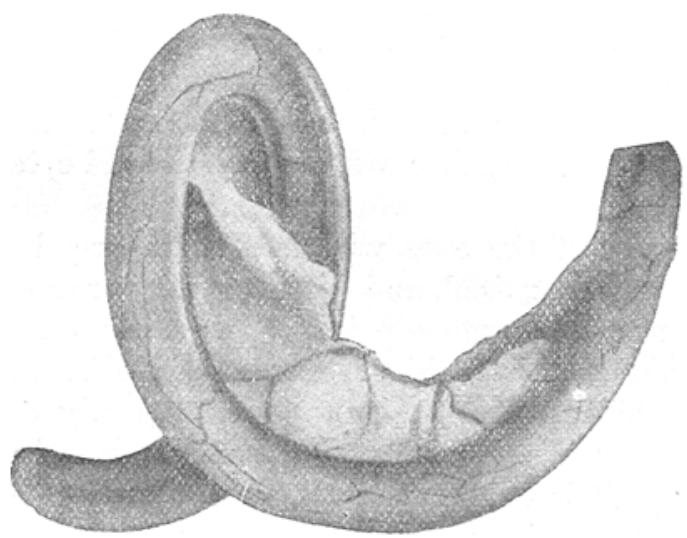

Fig. 6.-Cork.screw appendix.

in Douglas' pouch adhering to the posterior aspect of the ovary, while at the constricted part there was a band of adhesion to the terminal coil of the ilium. These relations accounted for the symptoms above referred to, and the removal of the appendix was followed by marked and permanent relief. 